\title{
Measuring Readability Levels of Undergraduate Investment Textbooks
}

\author{
Mojtaba Seyedian \\ SUNY Fredonia
}

\author{
Julie Fitzpatrick \\ SUNY Fredonia
}

\author{
Tai David Yi \\ SUNY Fredonia
}

Selection of a textbook for an introductory investment course can be challenging. Many criteria may be considered in such decisions, including a textbook's pedagogical approach, end-of-chapter material, and instructor supplements. Faculty may also wish to consider a text's readability, or the qualities of writing which are related to reader comprehension. Using the Flesch-Kincaid readability index, this study analyzes the predicted readability of five popular introductory investment textbooks. T-tests are performed to determine whether significant differences exist between the textbooks. Our results indicate that the Jordan/Miller/Dolvin textbook is the most readable while the Jones/Jensen textbook is the least readable among our sample. These findings can be useful to adopters and editors of introductory investment textbooks.

Keywords: readability, investment textbooks, Flesch-Kincaid grade level

\section{INTRODUCTION}

The selection of a textbook for use in introductory investment courses is an important decision for faculty. Since introductory investment is a required course in the typical finance curriculum, all the majors are affected by their decision. In fact, the recent shift to online learning accelerated by COVID-19 might further increase the importance of this decision since the textbook is a critical resource for online learners. But the text selection process is complicated by the large number of text attributes for faculty to consider. Such attributes may include: a text's pedagogical approach; coverage of material; exhibits, charts, and vignettes; end-of-chapter material; student and instructor supplements; and authors' reputations, as well as instructors' past experiences with the text. Faculty may also wish to consider a text's readability.

Readability may be defined as the degree to which a class of people finds certain reading matter compelling and comprehensible (McLaughlin, 1969). "Readability" should not be confused with "legibility," which refers to the ease of being read. Readability, in this context, refers to the qualities of writing which are related to reader comprehension. A variety of techniques have been used to predict readability, including several readability indexes (or formulas) which have been used widely since the 
1950s. Examples of readability indexes include SMOG (developed by McLaughlin), Flesch Reading Ease, Flesch-Kincaid Grade Level, Gunning-Fog, and Fry.

Information on readability can be helpful to faculty when making textbook adoption decisions. One of the criteria to which faculty attach the most significance in those decisions is textbook comprehensibility (Smith and DeRidder, 1997), which can be predicted, at least in part, using a readability index. Evidence also suggests that the higher the readability (difficulty) level of textbooks in core business courses, the lower the grade averages in those courses (Spinks and Wells, 1993).

\section{LITERATURE REVIEW}

A careful survey of literature identifies no readability study of introductory investment textbooks, per se. We found two articles that include the analysis of the readability of financial management textbooks. In one study, Gallagher and Thompson (1982), the authors apply the Flesch Reading Ease Index to seven textbooks in each of three disciplines: finance, management, and marketing. For the finance area, they showed that Weston and Brigham's Essentials of Managerial Finance $\left(1979,5^{\text {th }}\right.$ Edition) and Brigham's Fundamentals of Financial Management $\left(1980,2^{\text {nd }}\right.$ Edition) were the most readable textbooks of the time.

The most recent study of the readability of finance textbooks is that of Plucinski and Seyedian (2013). This study investigated whether there are significant differences in readability among five undergraduate corporate finance texts. Using the Flesch-Kincaid Grade Level index, the study found that Ross, Westerfield, and Jordan's Fundamentals of Corporate Finance (2010, 9th Edition) text was significantly more readable than the other four.

Other studies of readability in the field of finance have concerned corporate financial reports. Loughran and McDonald (2010), for example, uses the Fog Index to show that the easier-to-read 10-Ks contribute to greater capital markets efficiency and cause better corporate governance. Some of the studies of textbook readability for other business disciplines include: Gallagher and Thompson (1981) in economics, Pender, Stair, Stearns, and Villere (1976) in operations research, Raabe, Stevens, and Stevens (1984) in taxation, Razek, and Cone (1991) in business communication, Shuptrine and Licktenstein (1985) in marketing, Villere and Stearns (1976) in organizational behavior, Plucinski (2010) in accounting, and Seyedian, Walters, and Olsavsky (2019) in operations management.

\section{METHODS}

Undergraduate students usually take the introductory course in investment during their senior year, after completing the prerequisite courses in principles of finance, accounting, economics, statistics, and calculus in prior years. A typical introductory investment textbook is usually comprised of two general categories - a descriptive category about the various securities traded in the investment market and a quantitative one that deals with pricing and valuation of those securities. For this reason, the present study chooses the sample chapters for readability analysis such that they represent the two main topics in equal proportions.

The Gallagher and Thompson (1982) study uses the Flesch Reading Ease methodology, which is a function of the number of words per sentence and the number of syllables per word. The Willey et al (1998) study uses the Flesch-Kincaid readability index, which is based upon and related to the original Flesch index. Our study also uses the Flesch-Kincaid index, since it can be easily generated using word processing software; a large amount of text can thereby be readily analyzed with results that are objective and easily replicated.

\section{Flesch-Kincaid Grade Level}

The Flesch-Kincaid Grade Level has its roots in the Flesch Reading Ease formula developed in 1948 by Rudolf Flesch. In 1975, J. Peter Kincaid tested over 500 enlisted United States (U.S.) Navy personnel on a reading-comprehension test and also on passages from Navy training manuals. This enabled him to derive a version of the Flesch Reading Ease formula which yielded reading grade-level scores. The resulting 
Flesch-Kincaid Grade Level has since been adopted by the U.S. military services as the basis for deciding whether technical manuals from suppliers meet their readability requirements (Pearson, 2002). The FleschKincaid index is now one of the leading readability indexes. It is used extensively by the U.S. government and others, and it is included as a grammar-checking feature in the word processing software, Microsoft Word (MS-Word).

The Flesch-Kincaid Grade Level formula is based upon sentence length and word length. It rates text on a U.S. school grade level. For example, a score of 11.0 means that an eleventh grader can understand the document. The formula is:

$$
(0.39 \times \mathrm{ASL})+(11.8 \times \mathrm{ASW})-15.59
$$

where: $\mathrm{ASL}=$ average sentence length (the number of words divided by the number of sentences) ASW = average number of syllables per word (the number of syllables divided by the number of words)

(Pearson, 2002)

This study uses MS-Word to calculate the Flesch-Kincaid Grade Level of select passages. The formula used by MS-Word is confirmed by agreeing the formula above to that specified in the MS-Word help file. The MS-Word calculation is then validated by manually applying the formula above to a 200 -word passage and agreeing the result to that provided by the grammar-checking function in MS-Word.

\section{Selection and Adaptation of Text Passages}

An examination of the offerings of the four largest publishers of business textbooks in the United States yields about twenty introductory finance texts currently being published in English. That number does not include the many variations of the main texts by the same author(s). To make this study manageable, a subset is chosen for consideration. However, fairly selecting among the many alternatives is difficult. To make the results useful to the greatest number of instructors while limiting the number of texts, this study examines the most popular (best-selling) introductory investment textbooks.

Discussions with representatives of the four largest publishers of business textbooks in the United States yields five major introductory investment textbooks. An examination of the website, Amazon.com, confirms that the texts so identified are the five best-selling introductory investment textbooks at Amazon. The five texts are listed in Table 1, along with each textbook's particulars.

TABLE 1

INTRODUCTORY INVESTMENT TEXTBOOKS TESTED

\begin{tabular}{|l|l|l|l|l|c|}
\hline Authors & $\begin{array}{l}\text { Bodie, Kane \& } \\
\text { Marcus }\end{array}$ & Jones \& Jensen & $\begin{array}{l}\text { Jordan, Miller } \\
\text { \& Dolvin }\end{array}$ & Mayo & Smart \& Zutter \\
\hline Title & $\begin{array}{l}\text { Essentials of } \\
\text { Investments }\end{array}$ & $\begin{array}{l}\text { Investments: } \\
\text { Analysis and } \\
\text { Management }\end{array}$ & $\begin{array}{l}\text { Fundamentals } \\
\text { of Investments: } \\
\text { Valuation and } \\
\text { Management }\end{array}$ & $\begin{array}{l}\text { Investments: } \\
\text { An Introduction }\end{array}$ & $\begin{array}{l}\text { Fundamentals } \\
\text { of Investing }\end{array}$ \\
\hline Edition & 11 & 14 & 9 & 13 & 14 \\
\hline Copyright & 2019 & 2019 & 2021 & 2021 & 2020 \\
\hline Publisher & McGraw-Hill & Wiley & McGraw-Hill & Cengage & Pearson \\
\hline ISBN-13 & 9781260013924 & 9781119578123 & 9781260778632 & 9780357127957 & 9780135175217 \\
\hline
\end{tabular}




\begin{tabular}{|l|c|c|c|c|c|}
\hline Chapter Numbers Tested: & 1 & 1 & 2 & 1 & 1 \\
\hline $\begin{array}{l}\text { Investment } \\
\text { Environment }\end{array}$ & 2 & 2 & 3 & 1 & 1 \\
\hline Financial Instruments & 4 & 3 & 4 & $6 \& 7$ & 12 \\
\hline $\begin{array}{l}\text { Mutual Funds \& } \\
\text { ETFs }\end{array}$ & 3 & 4 & 5 & 2 & 2 \\
\hline Securities Markets & 8 & 12 & 7 & 4 & 9 \\
\hline $\begin{array}{l}\text { Market Efficiency } \\
\text { Efficient }\end{array}$ & 6 & 8 & 11 & 5 & 5 \\
\hline \begin{tabular}{l} 
Capital Asset Pricing \\
\hline
\end{tabular} & 7 & 9 & 12 & 5 & 5 \\
\hline
\end{tabular}

A review of the list of each text's ancillary materials reveals comparable offerings among the texts. For students, each text has a study guide and online study aids (for example, quizzes and/or spreadsheets). For instructors, each text has an instructor/solutions manual, a test bank, transparencies, PowerPoint presentations, and test generation software. All of the publishers distinguish their product in some way, usually with additional online material. However, it is expected that an instructor will subjectively evaluate the usefulness of any distinctive ancillaries. Therefore, an examination of ancillaries is beyond the scope of this study. This study is limited to the main textbook.

The seven topics selected for analysis from the five sample texts are, investment environment, financial instruments, mutual funds \& exchange-traded funds (ETFs), securities markets, market efficiency, efficient diversification, and capital asset pricing. See Table 1. However, in terms of the corresponding chapters, we choose six chapters from the Mayo text and five chapters from the Smart/Sutter text because the investment environment and financial instruments topics, and the efficient diversification and capital asset pricing topics, are combined into one chapter in each of the texts, while the mutual funds \& ETF topics are split into two chapters in the Mayo text. This approach of the content selection provides passages from the texts that cover about 30 percent of each textbook based upon an average of 21 chapters per text.

A hardcopy of each text is obtained from the publishers. Digital content is then obtained for each of the six target chapters of each textbook by electronically scanning the relevant pages with optical character recognition (OCR) software. All files are then imported into MS-Word for analysis.

Only the sentences in the body of the chapters are subjected to analysis. Appendices are excluded. Since the Flesch-Kincaid formula analyzes only sentences, all material in figures, exhibits, and headings is omitted from analysis. Since material in graphics and vignettes cannot be readily converted to plain text by word-processing software, it is also omitted. End-of-chapter material (e.g., vocabulary, review, problems) is omitted as well, since it is largely quantitative/ tabular in appearance and does not match the textual nature of the Flesch-Kincaid index.

When a colon appears at the end of a sentence, it is replaced with a period when the sentence is originally followed by a calculation, list, or figure. This is necessary because, in the Flesch-Kincaid calculation, MS-Word does not recognize a colon as the end of a sentence. Since calculations, lists, and figures are removed from the text, a sentence with a colon preceding a figure, for example, would have been combined with the one following the figure, thereby inflating the length of the sentence. In that case, replacing the colon with a period "ends" the sentence before the figure. Colons appearing in sentences that eventually ended in a period are unchanged. 
After converting, importing and pruning all files, the spelling and grammar function in MS-Word is applied to all files to correct occasional errors that arise and then to obtain the Flesch-Kincaid Grade Level. The text matter in the target chapters is not just sampled; the entire text matter of each of the seven target chapters of each textbook is subjected to the Flesch-Kincaid calculation.

\section{RESULTS}

\section{Comparison of Textbooks by Chapter}

Table 2 shows the Flesch-Kincaid Grade Levels for the seven target chapters of each textbook. The mean of the seven grade levels for each text (MGL) is also shown. Since the grade level indicates the U.S. school grade level required to understand a text passage, the lower the grade level the more readable the chapter.

TABLE 2

COMPUTED FLESCH-KINCAID GRADE LEVELS OF TEXTBOOK CHAPTERS

\begin{tabular}{|l|c|c|c|c|c|}
\hline Chapter Content & $\begin{array}{l}\text { Bodie, Kane } \\
\text { \& Marcus }\end{array}$ & $\begin{array}{l}\text { Jones \& } \\
\text { Jensen }\end{array}$ & $\begin{array}{l}\text { Jordan, } \\
\text { Miller \& } \\
\text { Dolvin }\end{array}$ & Mayo & \multicolumn{2}{|l|}{$\begin{array}{l}\text { Zmart \& } \\
\begin{array}{l}\text { Investment } \\
\text { Environment }\end{array}\end{array}$} & 12.7 & 13.6 & 9.8 & 9.8 & 12.3 \\
\hline Financial Instruments & 11.6 & 13.8 & 9.5 & 9.8 & 12.3 \\
\hline $\begin{array}{l}\text { Mutual Funds \& } \\
\text { ETFs }\end{array}$ & 12.1 & 13.2 & 9.5 & 10.8 & 11.8 \\
\hline Securities Markets & 12.0 & 13.0 & 10.5 & 11.4 & 11.5 \\
\hline Market Efficiency & 13.6 & 13.5 & 11.2 & 12.9 \\
\hline $\begin{array}{l}\text { Efficient } \\
\text { Diversification }\end{array}$ & 12.4 & 14.6 & 11.0 & 12.9 & 12.8 \\
\hline Capital Asset Pricing & 13.0 & 12.9 & 10.3 & 11.7 & 12.3 \\
\hline
\end{tabular}

An examination of Table 2 reveals that among the five textbooks analyzed, the Jordan/Miller/Dolvin textbook is the most readable (has the lowest grade level) for six of the seven chapters tested. For the Capital Asset Pricing chapter, the Jordan/Miller/Dolvin textbook has a grade level of 10.3, compared to a range of 12.8 to 13 for the other textbooks. Being the most difficult topic to explain in any introductory investment textbook, this low index is a welcome sign for students and instructors.

The best level for the Jordan/Miller/Dolvin text is 9.5 for the fundamental chapters, Financial Instruments (the range for the other texts for this chapter was 9.8 to 13.8) and Mutual Funds \& ETFs (the range for the other texts for this chapter was 10.8 to 13.2). The least readable Jordan/Miller/Dolvin chapter 
is Market Efficiency (11.2, compared to a range of 11.5 to 14 for the others). This result is expected, as the topic is fairly rigorous.

With a Mean Grade Level (MGL) of 10.3, the Jordan/Miller/Dolvin textbook appears to be the most readable by a wide margin. The Bodie/Kane/Marcus and Jones/Jensen texts, with MGLs of 12.5 and 13.5, respectively, appear to be the least readable textbooks. All five textbooks on average were less readable for the last three chapters tested. This is perhaps because the last three chapters deal with more quantitative topics which results in lesser amount of verbiage.

\section{Overall Comparison of Textbooks}

The results in the previous section where we compare the textbooks chapter by chapter are based on sample passages relative to the entire text. Therefore, using the paired t-test, we determine whether there exists a significant difference of the Mean Grade Levels (MGLs) between the texts. In doing so, we perform the t-test on the sample means without equality of variances assumed. Table 3 shows $p$-values for the differences between the paired MGLs. The Jordan/Miller/Dolvin textbook is clearly the most readable. Its MGL of 10.3 is significantly lower than the other textbooks' at the one percent level of significance. The Jones/Jensen textbook, with a mean of 13.5, is the least readable because its MGL is significantly higher than those of Smart/Zutter and Jordan/Miller/Dolvin at the one percent level and those of Mayo and Bodie/Kane/Marcus at the five percent level. In addition, Table 3 reports the MGLs of 11.7, 12.3, and 12.5 for the Mayo, Smart/Zutter, and Bodie/Kane/Marcus texts, respectively. However, there is no significant difference of the MGLs between the texts even at the ten percent level.

TABLE 3

T-TEST RESULTS: P-VALUES OF DIFFERENCES BETWEEN TEXTBOOK MEAN GRADE LEVELS (MGLS)

\begin{tabular}{|c|c|c|c|c|c|}
\hline $\begin{array}{l}\text { Textbook Author, et } \\
\text { al. (MGL) }\end{array}$ & & & & & \\
\hline \multicolumn{6}{|l|}{ Bodie (12.5) } \\
\hline Jones (13.5) & $.028 * *$ & & & & \\
\hline Jordan (10.3) & $.000^{* * *}$ & $.000 * * *$ & & & \\
\hline Mayo (11.7) & .129 & $.029 * *$ & $.014 * * *$ & & \\
\hline \multirow[t]{3}{*}{ Smart (12.3) } & .688 & $.006^{* * *}$ & $.001^{* * *}$ & .352 & \\
\hline & Bodie (12.5) & Jones (13.5) & Jordan (10.3) & Mayo (11.7) & Smart (12.3) \\
\hline & \multicolumn{5}{|c|}{ Textbook Author, et al. (MGL) } \\
\hline
\end{tabular}

Notes:

*** Statistically significant difference at the .01 level;

** Statistically significant difference at the .05 level;

* Statistically significant difference at the .10 level.

\section{CONCLUSION}

Selecting a textbook is one of the most important decisions a faculty member can make in designing a course. As more courses are taught remotely, the decision carries even greater importance since the textbook is a key resource to facilitate online learners' understanding of course material.

Readability is one factor that can be useful in textbook selection. Using MS-Word to calculate the Flesch-Kincaid Grade Level, we evaluate the readability of five widely used introductory investment textbooks. Our results indicate that the Jordan/Miller/Dolvin textbook is the most readable, with a MGL (10.3) significantly lower than the MGLs of the other textbooks examined. We find the Jones/Jensen 
textbook, with a MGL of 13.5, to be the least readable among our sample. These results can be useful to instructors when making textbook adoption decisions for Investment courses.

Editors of introductory finance texts can also use these findings. Long, complicated sentences, while sometimes necessary, may hinder a student's comprehension when used extensively. Textbook editors may use these findings to set their expectations of authors of future introductory finance textbooks.

\section{REFERENCES}

Brigham, E.F. (1980). Fundamentals of Financial Management (2nd Edition). Dryden Press, Hinsdale.

Gallagher, D.J., \& Thompson, G. (1982). Textbooks in management, marketing and finance: An analysis of readability. Journal of Business Education, 57(4), 149-151.

Gallagher, D.J., \& Thompson, G. (1981, Summer). A readability analysis of selected introductory economics textbooks. Journal of Economic Education, pp. 60-63.

Loughran, T., \& McDonald, B. (2010). Measuring readability in financial text. Social Science Research Network. Retrieved from http://papers.ssrn.com

McLaughlin, G.H. (1969). SMOG grading - A new readability formula. Journal of Reading, 22, 639646.

Pearson, P.D. (2002). Handbook of Reading Research. Lawrence Erlbaum Associates, Mahwah.

Pender, B., Stair, R., Stearns, G., \& Villere, M. (1976). The readability of operations research and operations management textbooks. Interfaces, 7(1), 99-105.

Plucinski, K.J., \& Seyedian, M. (2013). Readability of introductory finance textbooks. Journal of Financial Education, 39(1/2), 43-52.

Plucinski, K.J. (2010). Readability of intermediate accounting textbooks. Academy of Educational Leadership Journal, 14(2), 49-57.

Raabe, W.A., Stevens, K., \& Stevens, W. (1984). Tax textbook readability: An application of the cloze method. Journal of American Taxation Association, 6(1), 66-73.

Razek, J.R., \& Cone, R. (1976). Readability of business communication textbooks - An empirical study. Journal of Business Communication, 18(2), 33-40.

Ross, S.A., Westerfield, R., \& Jordan, B. (2010). Fundamentals of Corporate Finance (9th Edition). McGraw-Hill, New York.

Seyedian, M., Walters, L., \& Olsavsky, J. (2019). A readability analysis of undergraduate textbooks in operations management. Journal of Business, Economics and Technology, 22(1), 175-181.

Shuptrine, F.K., \& Licktenstein, D. (1985). Measuring readability levels of undergraduate marketing textbooks. Journal of Marketing Education, 7(3), 38-45.

Smith, K.J., \& DeRidder, J. (1997). The selection process for accounting textbooks: General criteria and publisher incentives - A survey. Issues in Accounting Education, 12(2), 367-384.

Spinks, N., \& Wells, B. (1993). Readability: A textbook selection criterion. Journal of Education for Business, 69(2), 83-88.

Villere, M.F., \& Stearns, G. (1976). The readability of organizational behavior textbooks. The Academy of Management Journal, 19(1), 132-137.

Weston, J.F., \& Brigham, E. (1979). Essentials of Managerial Finance (5th Edition). Dryden Press, Hinsdale.

Willey, T., Willey, L., \& Mendez, J. (1998, Fall). The readability of undergraduate corporate finance texts. Journal of Financial Education, pp. 31-34. 